\title{
MOLECULAR PHYLOGENETICS OF THE POSSIBLY EXTINCT MARTINIQUE GROUND SNAKE
}

\author{
Michael J. Jowers ${ }^{1,3,4}$, Stephane Caut $^{1,3}$, Juan Luis Garcia-Mudarka ${ }^{1}$, Samer Alasaad ${ }^{1}$, and \\ IVAN INEICH $^{2}$ \\ ${ }^{1}$ Estación Biológica de Doñana (CSIC), Av. Americo Vespucio, 41092, Sevilla, Spain \\ ${ }^{2}$ Muséum national d'Histoire naturelle, Département Systématique et Evolution, UMR CNRS 7205 (Origine, Structure et \\ Evolution de la Biodiversité)-25, rue Cuvier, Reptiles and Amphibiens, Case Postale 30, 75005 Paris, France
}

\begin{abstract}
Aвstract: The Lesser Antilles is a biodiversity hot spot but unfortunately human disturbance has taken its toll, causing dramatic population declines and even extinction of numerous endemic species. Nevertheless, today the rediscovery of previously thought extinct species is not uncommon. Often, old museum specimens and their original descriptions are the only information available for such species. The application of molecular phylogenetic relationships to extant species can help to elucidate pivotal information on their ecology and conservation. Erythrolamprus cursor is possibly an extinct colubrid racer from Martinique, currently classified as critically endangered on the International Union for Conservation of Nature Red List. Mitochondrial deoxyribonucleic acid sequences were obtained from four E. cursor specimens from the Muséum national d'Histoire naturelle (Paris) collections. All sequences recovered the same haplotype and the level of divergence between E. cursor and E. juliae, from the nearby island of Dominica, was lower than between other intraspecific distances within other Erythrolamprus. Furthermore, phylogenetic analyses confirm that these two species are sister taxa and share most recent common ancestry. We discuss that published ecological data available for the sister species (E. juliae) may help to elucidate information on this species' natural history, ultimately having important implications for a future conservation management program if E. cursor is to be found. We emphasize the urgent need to conduct an exhaustive survey on the supposed last population of E. cursor at Diamond Rock to establish the survival of this species there, to understand how it may have adapted to such an ecosystem, especially in sympatry of several introduced rodent species.
\end{abstract}

Key words: Dominica; Erythrolamprus cursor; Extinction; Liophis; Mitochondrial DNA; Predator eradication; West Indies

FOR THE LAST DECADE, rediscoveries of previously thought extinct species have been the focus of interest to conservationists, biogeographers, and systematists (Crowley, 2011; Ladle et al., 2011). A recent review estimated that over the past $122 \mathrm{yr}$, at least 351 species have been rediscovered, most of them in the tropics (Scheffers et al., 2011). The number of rediscoveries has increased over time, mostly by the combination of technology and improved access to the localities where these species are found, making the finding of such species easier than ever. However, the majority of species are only known from just one or a few museum specimens that were collected decades or even centuries earlier (Ladle et al., 2011). Thus, rediscoveries generate new conservation efforts to preserve such species and help

\footnotetext{
${ }^{3}$ These two authors contributed equally to this work.

${ }^{4}$ Correspondence: e-mail, michaeljowers@hotmail. com
}

to resolve the understanding of population declines as a consequence of human disturbance (Fisher, 2011; Fisher and Blomberg, 2011).

On the basis of the concentration of endemic species and habitat degradation, the West Indies is considered a biodiversity hot spot (Myers et al., 2000). Because of their geography (33 islands of contrasting sizes) and the high level of endemisms, the Lesser Antilles poses a unique example to address biogeographical questions. These islands harbor 25 snake species (five families); $87.5 \%$ of them are endemic and some are among the rarest in the world (Henderson, 2004). Because island ecosystems are well known to be more vulnerable than continental ecosystems, the populations of such ecosystems are especially vulnerable to human disturbance (Simberloff, 2000). Furthermore, these islands have had at least six, and possibly as many as 11, historical extirpations (e.g., Alsophis, Erythrolamprus; Henderson, 2004). 
Within the family Colubridae, the former genus Liophis Wagler, 1830 (now Erythrolamprus and Lygophis, Grazziotin et al., 2012) evidences a high diversity, with about 41 species inhabiting Central and South America, but also several islands. These snakes have a small to moderate body size (total length between 500 and $1500 \mathrm{~mm}$ ) and are basically terrestrial, although some are semiaquatic. These species can be found in humid environments such as primary and secondary forests, flooded forests, and floodplains, as well as in dry habitats such as semiarid scrubland and open pastures (Dixon, 1980). Among them only four species are found in the Lesser Antilles: two extinct (Erythrolamprus ornatus from Saint Lucia and $E$. perfuscus from Barbados), one of them present on three islands (E. juliae, Dominica, Guadeloupe, and Marie-Galante), and the critically endangered endemic colubrid racer E. cursor from Martinique (Powell and Henderson, 2005). This latter species was common throughout Martinique (French West Indies) during the 18th and 19th centuries (Moreau de Jonnès, 1818). However, few have been the sightings for the last half of the century. Despite the fact that there have been several reports from the 1970s, the last observation of this colubrid in Martinique is of one individual caught in 1965 in the vicinity of Fort-de-France. Furthermore, the last published records are from Diamond Rock, a small islet (5.8 ha) that lies $2 \mathrm{~km}$ south from Martinique, in 1962 (Lazell, 1967), and two additional specimens were collected at this locality in 1964 and 1968 (Breuil, 2009; Fig. 1). In addition, fishermen have reported a snake basking on the rocks of Diamond Rock. In an attempt to find this snake, Michel Breuil and Mark Day searched Diamond Rock in 1997 with no success (Breuil, 2009). Thus, lack of any official sightings of this snake for $44 \mathrm{yr}$ suggests that it is quite likely that it may have recently become extinct (Honegger, 1981).

The reasons for such a drastic population decline are not clear. However, introduced predators such as cats and mongooses may be taking their toll on its populations and other species (Lorvelec et al., 2007). In the West Indies, Small Indian Mongooses (Herpestes auropunctatus) are thought to be the major species responsible for reptile extirpations or declines since 1836 (Henderson, 1992). Three Erythrolamprus species are thought to have been extirpated after the introduction of mongooses on islands: E. cursor from Martinique, E. melanotus from Grenada, and E. ornatus from Saint Lucia and now confined to a mongoose-free small islet (Maria Major). To make matters worse, confusion between $E$. cursor and the venomous Martinique Lancehead (Bothrops lanceolatus) of Martinique may have led to eradication of the former by humans (Breuil, 2009). The last-thought locality of E. cursor, Diamond Rock, could be the last refuge for this species by lack of mongoose predators. However, Black Rats (Rattus rattus) were introduced by English and French settlements during the Napoleonic Wars (Breuil, 2009) and may constitute a threat to E. cursor, mainly by clutch predation.

As with most species that have not been seen since the 1950s, little is known about their ecology. Therefore it is very difficult to know where and how to search for them but also how to develop an efficient conservation program. One way to better understand their ecology is through museum collection specimens, but unfortunately, apart from morphological descriptions, the specimens may have empty stomachs. One other possibility is to focus on the museum species' closest living relatives for which ecological data may be available to attempt to better understand their ecology. Thus, there has been an increase in the use of genetic analyses on museum specimens to assess their phylogenetic relationships and biogeography in recent years (Wandeler et al., 2007). In our study, we first attempted to amplify mitochondrial gene fractions (12S and $16 \mathrm{~S}$ ribosomal deoxyribonucleic acid [rDNA] and mini bar coding COI) from E. cursor old museum preserved specimens (collection dates ranging from 1866 to 1910). Second, we constructed a phylogeny to assess the level of genetic divergence and phylogenetic relationships to other available Erythrolamprus species. Third, we hoped that by identifying $E$. cursor's closest relative for which ecological data could be available, we would elucidate new information on its 


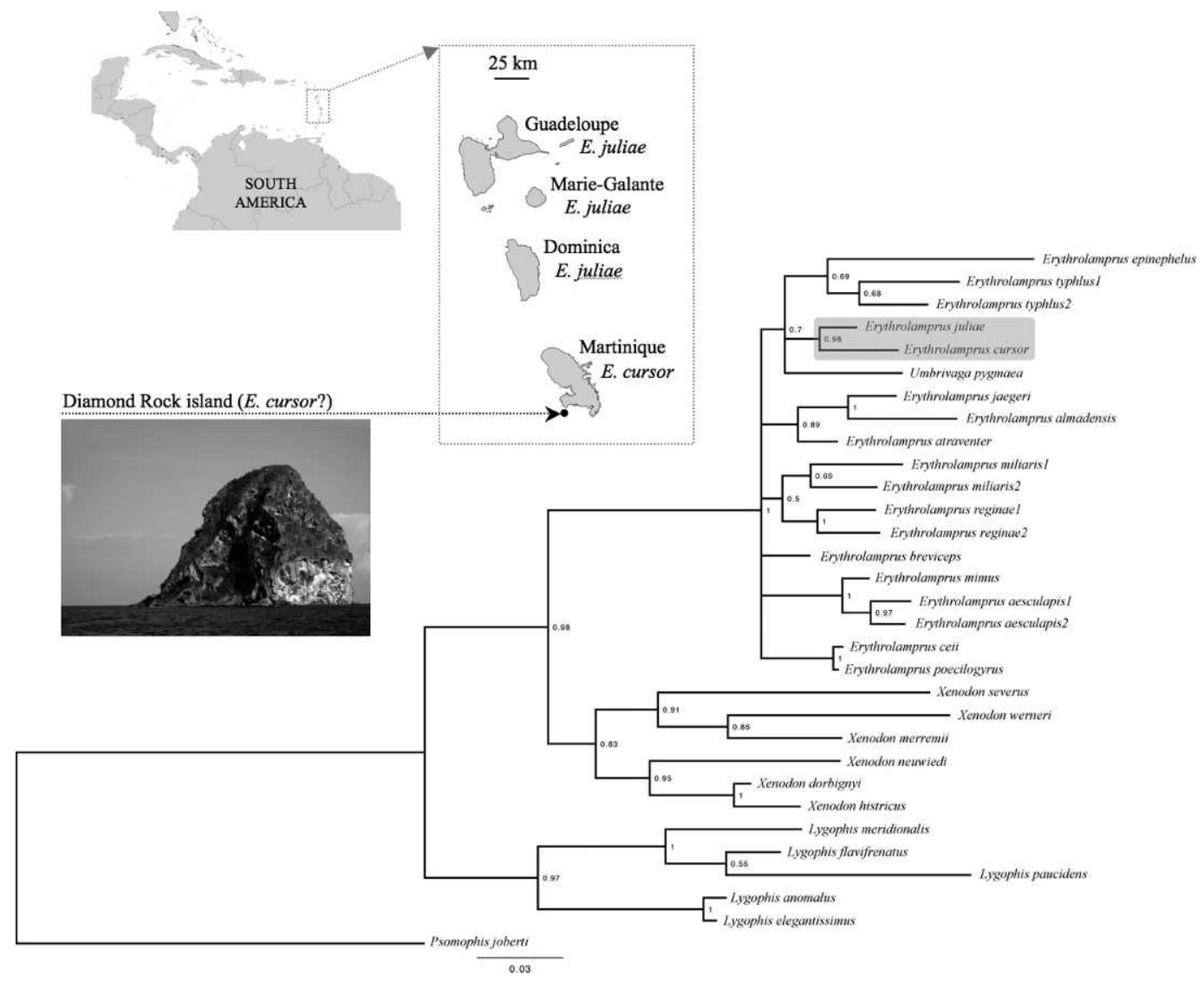

FIG 1.-Distribution map of Erythrolamprus juliae and E. cursor in the West Indies with photograph of Diamond Rock (copyright by apmarles) and Bayesian inference 50\% consensus phylogram of all available Xenodontini species (12S and 16S rDNA partial genes). Values by nodes are the posterior probabilities recovered from the Bayesian analysis. E. juliae and E. cursor are shown in a shaded background.

ecology, help to clarify its taxonomic status, and contribute to this species' conservation. Last, we discuss the importance of establishing the presence of E. cursor on Diamond Rock, where it was last sighted, and address the need to develop a conservation program to preserve the last individuals of this species, if they are ever found.

\section{Materials and Methods Molecular Analyses}

Genomic DNA was extracted from eleven Muséum national d'Histoire naturelle (MNHN, Paris) museum specimens (Table 1) following standard phenol/chloroform procedures (Sambrook et al., 1989) with DNA precipitation overnight. DNA extractions were carried out in a sterile laboratory exclusively for low-DNA-concentration samples. Negative controls were included in each extraction to monitor for contamination. We aimed to amplify a fraction of the mitochondrial (mt) $12 \mathrm{~S}$ and $16 \mathrm{~S}$ rDNA genes with mitochondrial vertebrate universal primers (Kocher et al., 1989; Palumbi et al., 1991) to compare our sequences with other published Erythrolamprus species available from Genbank. However, all attempts to amplify $12 \mathrm{~S}$ and $16 \mathrm{~S}$ rDNA were unsuccessful due to human DNA contamination. Thus, we designed $12 \mathrm{~S}$ and 16S rDNA primers that would match specifically to Erythrolamprus published sequences and not human DNA (Table 2). Because binding sites at the $3^{\prime}$ and $5^{\prime}$ prime ends of the 
Table 1.-Erythrolamprus cursor specimen information table for which DNA amplification was attempted.

\begin{tabular}{|c|c|c|c|c|c|c|c|c|}
\hline ID & MNHN ID & Origin & Donor & Date & Sex & Total size $^{\mathrm{b}}$ & Tail size $^{b}$ & Subcaudals $^{c}$ \\
\hline $1^{\mathrm{a}}$ & 1887.0120 & Martinique & Mr Lemaire & 5 March 1887 & $\mathrm{~F}$ & 86 & 24.5 & 101 \\
\hline 2 & 1886.0174 & Martinique & Mr H. Deyrolle & 21 July 1886 & $\mathrm{~F}$ & 82.5 & 24.5 & 107 \\
\hline 3 & 1907.0170 & Martinique & Mr Lahille & 10 September 1907 & $\mathrm{~F}$ & 72 & 21 & 102 \\
\hline $4^{\mathrm{a}}$ & 1891.0246 & Martinique & Mr F. Bocourt & 30 July 1891 & $\mathrm{M}$ & 62.5 & 16 & 77 \\
\hline 5 & 8614 & Antilles & Faculty of science & & $\mathrm{F}$ & 90 & 27.5 & 110 \\
\hline 6 & $8614 \mathrm{~A}$ & Antilles & Faculty of science & & $\mathrm{F}$ & 87 & 33 & 114 \\
\hline 7 & 8614B & Antilles & Faculty of science & & $\mathrm{F}$ & 93 & 27 & 103 \\
\hline 8 & 0218 & Brazil? & Mr Vautier & & $\mathrm{F}$ & 81 & 23 & 104 \\
\hline $9^{\mathrm{a}}$ & 3544 & Cayenne & Mr Robert & & $\mathrm{F}$ & 86 & 26 & 103 \\
\hline 10 & 1990.4986 & & Mr Roux & 1990 & M & 61 & 20 & 89 \\
\hline $11^{\mathrm{a}}$ & $\begin{array}{l}\text { MNHN } \\
\text { unregistered }\end{array}$ & Martinique & $\begin{array}{l}\text { Collection } \\
\text { Westphal-Castelnau }\end{array}$ & Before 1869 & $\mathrm{~F}$ & 90.7 & 25.5 & 105 \\
\hline
\end{tabular}

\footnotetext{
a Denotes successful amplification and sequencing. MNHN: Muséum national d'Histoire naturelle, Paris, France.

b Total size and Tail size in centimeters.

c Scale counts.
}

genes were not suitable to amplify speciesspecific primers, we designed two internal $12 \mathrm{~S}$ and 16S rDNA (forward and reverse) primers to amplify with universal markers (Table 2).

Following the polymerase chain reactions (PCRs), excess primers and deoxyribonucleotide triphosphates were removed using enzymatic reaction of Escherichia coli exonuclease I, Antartic phosphatase, and Antartic phosphatase buffer (all New England Biolabs). Sequencing was carried out in both directions using the BigDye ${ }^{\circledR}$ Terminator v1.1 cycle sequencing kit (Applied Biosystems) according to the manufacturer's instructions. Labeled fragments were resolved on an automated A3130xl genetic analyzer (Applied Biosystems). Incomplete terminal sequences and PCR primers were removed.

Templates were sequenced on both strands, and the complementary reads were used to resolve rare, ambiguous base-calls in Sequencher v.4.9. Sequences were aligned in
Seaview v.4.2.12 (Gouy et al., 2010) under Muscle (Larkin et al., 2007) default settings. Nucleotide substitutions and $p$-uncorrected distances were performed with PAUP*4.b.10 (Swofford, 2002), and phylogenetic analyses were performed with MrBayes v.3.1.2 (Huelsenbeck and Ronquist, 2001). Because two genera within the Xenodontini (Lygophis, Erythrolamprus) have undergone recent important taxonomic changes (Grazziotin et al., 2012), all species belonging to these two genera for which $12 \mathrm{~S}$ and $16 \mathrm{~S}$ rDNA fractions (from Zaher et al., 2009, and Vidal et al., 2010; Grazziotin et al., 2012) were available were included in the analyses to corroborate the phylogenetic position of the former Liophis (= Erythrolamprus) cursor (genbank accessions JX905303-14). Additionally, Umbrivaga pygmaea, which has shown to be monophyletic with Erythrolamprus (Vidal et al., 2010; Grazziotin et al., 2012), was also included in the analysis. Four species for which sequences

Table 2.- Primers used to amplify and sequence $12 \mathrm{~S}$ and 16S rDNA and COI (mini bar coding with M13).

\begin{tabular}{lll}
\hline Name & \multicolumn{1}{c}{ Sequence } & \multicolumn{1}{c}{ Reference } \\
\hline 12SA & 5'-AAACTGGGATTAGATACCCCACTAT-3' & Kocher et al., 1989 \\
12SB & 5'-GAGGGTGACGGGCGGTGTGT-3' & Kocher et al., 1989 \\
16SL & 5'-GCCTGTTTATCAAAAACAT-3' & Palumbi et al., 1991 \\
16SH & 5'-CCGGTCTGAACTCAGATCACGT- 3' & Palumbi et al., 1991 \\
Lio16SF & 5'-TAAACTGATCTACCAGTAAAAAAGCTGGA-3' & This study \\
Lio16SR & 5'-AGTAACTTGGTTCAATTYTCAGGTG-3' & This study \\
Lio12SF & 5'-GTCGCCAGCTTACCTTGYAAAAGAA-3' & This study \\
Lio12SR & 5'-GTTTTAGTTTCATYGTTTATCCGTG-3' & This study \\
Mini bar code COI F & 5'-TCCACTAATCACAARGATATTGGTAC-3' & Meusnier et al., 2008 \\
Mini bar code COI R & 5'-GAAAATCATAATGAAGGCATGAGC-3' & Meusnier et al., 2008 \\
\hline
\end{tabular}


were available (E. typhlus, E. milliaris, E. reginae, and $E$. aescupalis) were included in the analyses to compare for intraspecific genetic divergence between them. The designated outgroup was Psomophis joberti, which, on the basis of ribosomal and nuclear gene fractions, has shown to be basal to the genus (Grazziotin et al., 2012; Supplementary Material).

The most appropriate substitution model for the Bayesian inference was determined by the Bayesian information criterion (BIC) in jModeltest v.0.1.1 (Posada, 2008). MrBayes was used with default priors and Markov chain settings and with random starting trees. The gamma shape parameter and proportion of invariant sites were estimated from the data. Each run consisted of four chains of $10,000,000$ generations, sampled each 10,000 generations for a total of 1000 trees. A plateau was reached after a few generations, with $25 \%$ (250 trees) of the trees resulting from the analyses discarded as "burn in."

\section{Results}

One specimen amplified successfully for all primer pairs (both fractions of the $12 \mathrm{~S}$ and 16S rDNA and mini bar code COI, specimen ID 1). In addition, three other individuals (specimens ID: 4, 9, 11) amplified the second fraction of the $12 \mathrm{~S}$ rDNA and the mini bar code COI (113 base pairs [bp]; Table 1). Alignment of all four individuals for these two gene fractions showed no variation, all sequences being identical. Genbank blast searches matched Erythrolamprus.

The alignment with all species that resulted from the 12S (336 bp) and 16S rDNA (413 bp) fragments was $749 \mathrm{bp}$ in length (Fig. 1). The best-fitting model for the Bayesian tree was the $\mathrm{TIM} 2+\mathrm{G}(-\operatorname{lnL}=-3961.4549, \mathrm{BIC}=$ 8372.9842).

The Bayesian $50 \%$ consensus phylogram recovered three well-supported clades constituted by each of the Xenodontini genera (Lygophis, Xenodon, and Erythrolamprus; Bayesian Posterior Probability $(\mathrm{BPP})=0.97$, $0.83,1.0$ respectively). Lygophis is basal to Xenodon and Erythrolamprus, in accordance with the topology of the Xenodontini obtained by Grazziotin et al. (2012). Interestingly, $E$. juliae from Dominica and E. cursor from
Martinique were monophyletic and strongly supported (BPP $=0.98$, Fig. 1). Thus, the phylogenetic relationship between E. cursor and E. juliae is better supported than between other intraspecific relationships such as $E$. typhlus $(\mathrm{BPP}=0.68)$, E. miliaris $(\mathrm{BPP}=0.69)$, and $E$. aesculapis $(\mathrm{BPP}=0.97)$.

The phylogenetic position of both species is further supported by the uncorrected $p$ distances between them, being within the lowest of the genus-interspecific comparisons $(2.0 \%$, Table 3$)$. Comparatively, pair-wise differences between E. typhlus (3.6\%), E. miliaris $(3.4 \%)$, and E. reginae $(2.6 \%)$ showed a higher genetic divergence than between $E$. juliae and E. cursor.

\section{Discussion \\ Phylogenetic Classification}

We successfully amplified mtDNA (12S and 16S rDNA $674 \mathrm{bp}, 278$ and 396 bp respectively, and mini bar coding COI, $113 \mathrm{pb}$ ) from four E. cursor individuals from a total of 11 specimens from the MNHN collections. Considering the collection dates (around 1900; Table 1) and the high human DNA contamination, this result was unexpected. Thus, to overcome the contamination problem we designed specific primers for Erythrolamprus, which hereafter can be used for future molecular studies to amplify Erythrolamprus mtDNA, such as from the extinct $E$. perfuscus from Barbados or E. ornatus from Saint Lucia.

Our results strongly support that E. cursor and E. juliae are monophyletic and share recent common ancestry. Furthermore, their sister clade relationship to E. epinephelus $+E$. typhlus $+U$. pygmaea suggests long-term isolation in the West Indies islands from where they are endemic (Fig. 1). The low genetic divergence between E. juliae and E. cursor (being similar or lower to other intraspecific genetic differentiation within the genus) may suggest that these are closely related species, sharing most recent common ancestry. This is further supported by the fact that the small geographical distance between Dominica and Martinique $(40 \mathrm{~km})$ does not seem enough to prevent gene flow from one island to another for successful oversea 
Table 3.-Nucleotide substitutions (above diagonal) and $p$-uncorrected distances (below diagonal) for each pair-wise comparison between all Xenodontini species and outgroup. Numbers in bold correspond to nucleotide substitutions and genetic distances between $E$. juliae and $E$. cursor.

\begin{tabular}{|c|c|c|c|c|c|c|c|c|c|c|c|c|c|c|c|}
\hline & E.epi & E.typI & E.typ 2 & E.jae & E.jul & E.cur & U.pyg & E.mil2 & E.mill & E.bre & E.mim & E.reg2 & E.reg1 & E.ael & E.ae2 \\
\hline E.epi & - & 39 & 36 & 45 & 38 & 39 & 41 & 41 & 45 & 35 & 46 & 42 & 41 & 48 & 48 \\
\hline E.typ1 & 0,059 & - & 23 & 40 & 28 & 30 & 31 & 38 & 40 & 34 & 39 & 39 & 37 & 41 & 41 \\
\hline E.typ2 & 0,057 & 0,036 & - & 32 & 25 & 26 & 32 & 32 & 36 & 31 & 30 & 31 & 32 & 35 & 35 \\
\hline E.jae & 0,068 & 0,056 & 0,049 & - & 28 & 33 & 40 & 35 & 31 & 30 & 30 & 30 & 27 & 34 & 34 \\
\hline E.jul & 0,06 & 0,043 & 0,038 & 0,043 & - & 13 & 24 & 25 & 27 & 20 & 27 & 25 & 25 & 32 & 32 \\
\hline E.cur & 0,064 & 0,045 & 0,043 & 0,049 & 0,022 & - & 27 & 31 & 23 & 21 & 30 & 28 & 25 & 33 & 33 \\
\hline U.pyg & 0,062 & 0,047 & 0,051 & 0,061 & 0,038 & 0,045 & - & 30 & 36 & 27 & 37 & 32 & 33 & 39 & 39 \\
\hline E.mi2 & 0,062 & 0,053 & 0,049 & 0,049 & 0,039 & 0,046 & 0,046 & - & 22 & 19 & 29 & 21 & 23 & 29 & 29 \\
\hline E.mill & 0,071 & 0,062 & 0,055 & 0,048 & 0,041 & 0,038 & 0,057 & 0,034 & - & 23 & 28 & 27 & 24 & 33 & 33 \\
\hline E.bre & 0,055 & 0,053 & 0,047 & 0,046 & 0,031 & 0,035 & 0,043 & 0,029 & 0,035 & - & 23 & 23 & 21 & 30 & 30 \\
\hline E.mim & 0,07 & 0,059 & 0,047 & 0,045 & 0,043 & 0,049 & 0,056 & 0,044 & 0,044 & 0,036 & - & 27 & 28 & 11 & 11 \\
\hline E.reg2 & 0,064 & 0,055 & 0,048 & 0,042 & 0,039 & 0,042 & 0,049 & 0,029 & 0,042 & 0,036 & 0,041 & - & 17 & 28 & 28 \\
\hline E.reg1 & 0,065 & 0,057 & 0,049 & 0,042 & 0,038 & 0,041 & 0,052 & 0,035 & 0,037 & 0,032 & 0,044 & 0,026 & - & 33 & 33 \\
\hline E.ael & 0,073 & 0,053 & 0,052 & 0,05 & 0,051 & 0,057 & 0,058 & 0,045 & 0,055 & 0,045 & 0,02 & 0,043 & 0,046 & - & 11 \\
\hline E.ae2 & 0,076 & 0,064 & 0,054 & 0,053 & 0,049 & 0,055 & 0,062 & 0,045 & 0,051 & 0,046 & 0,017 & 0,044 & 0,051 & 0,017 & - \\
\hline E.alm & 0,066 & 0,06 & 0,059 & 0,032 & 0,051 & 0,057 & 0,068 & 0,054 & 0,052 & 0,054 & 0,055 & 0,049 & 0,054 & 0,052 & 0,058 \\
\hline E.atr & 0,068 & 045 & 0,045 & 0,026 & 037 & 0,042 & 0,047 & 0,04 & 0,045 & 0,034 & 0,036 & 0,038 & 0,037 & 0,041 & 0,047 \\
\hline E.cei & 0,059 & 0,049 & 0,043 & 0,049 & 0,036 & 0,045 & 0,046 & 0,032 & 0,037 & 0,026 & 0,033 & 0,035 & 0,031 & 0,041 & 0,04 \\
\hline E.poe & 0,058 & 0,048 & 0,042 & 0,047 & 0,034 & 0,045 & 0,044 & 0,031 & 0,035 & 0,025 & 0,032 & 0,034 & 0,029 & 0,039 & 0,039 \\
\hline L.fla & 0,115 & 0,107 & 0,116 & 0,107 & 0,105 & 0,105 & 0,108 & 0,102 & 0,109 & 0,095 & 0,115 & 0,1 & 0,108 & 0,109 & 0,117 \\
\hline L.mer & 0,116 & 0,107 & 0,115 & 0,112 & 0,106 & 0,109 & 0,109 & 0,103 & 0,112 & 0,093 & 0,113 & 0,108 & 0,107 & 0,108 & 0,114 \\
\hline L.ano & 0,122 & 0,115 & 0,118 & 0,112 & 0,109 & 0,107 & 0,11 & 0,108 & 0,116 & 0,101 & 0,123 & 0,104 & 0,11 & 0,112 & 0,117 \\
\hline L.ele & 0,117 & 0,112 & 0,115 & 0,109 & 0,104 & 0,104 & 0,105 & 0,105 & 0,111 & 0,096 & 0,119 & 0,101 & 0,105 & 0,109 & 0,117 \\
\hline L.pau & 0,14 & 0,142 & 0,129 & 0,125 & 0,151 & 0,162 & 0,147 & 0,122 & 0,147 & 0,123 & 0,14 & 0,125 & 0,126 & 0,126 & 0,13 \\
\hline X.sev & 0,122 & 0,112 & 0,109 & 0,111 & 0,101 & 0,102 & 0,118 & 0,098 & 0,098 & 0,1 & 0,108 & 0,1 & 0,09 & 0,1 & 0,105 \\
\hline wer & 0,125 & 0,114 & 0,112 & 0,106 & 0,102 & 0,117 & 0,113 & 0,107 & 0,105 & 0,098 & 0,11 & 0,101 & 0,095 & 0,111 & 0,112 \\
\hline t.neu & 0,097 & 0,098 & 0,096 & 0,092 & 0,093 & 0,098 & 0,093 & 0,09 & 0,091 & 0,085 & 0,09 & 0,088 & 0,087 & 0,087 & 0,09 \\
\hline mer & 0,123 & 0,114 & 0,109 & 0,098 & 0,112 & 0,12 & 0,116 & 0,12 & 0,123 & 0,119 & 0,113 & 0,104 & 0,098 & 0,108 & 0,113 \\
\hline x.dor & 0,102 & 0,107 & 0,097 & 0,09 & 0,091 & 0,087 & 0,095 & 0,079 & 0,077 & 0,081 & 0,09 & 0,087 & 0,082 & 0,088 & 0,091 \\
\hline X.his & 0,097 & 0,105 & 0,104 & 0,094 & 0,095 & 0,096 & 0,095 & 0,084 & 0,087 & 0,088 & 0,093 & 0,083 & 0,085 & 0,09 & 0,095 \\
\hline P.job & 0,15 & 0,139 & 0,151 & 0,142 & 0,14 & 0,143 & 0,143 & 0,134 & 0,147 & 0,139 & 0,161 & 0,143 & 0,15 & 0,151 & 0,162 \\
\hline
\end{tabular}

dispersers such as snakes. Furthermore, the presence of Erythrolamprus endemics throughout the West Indies islands (E. perfuscus in Barbados, the extinct E. ornatus in Saint Lucia, E. cursor in Martinique, and E. juliae in Dominica, Guadeloupe, and MarieGalante; Henderson, 1992, 2004; Powell and Henderson, 2012) and the fact that these islands have never been joined geographically to others through land-bridge connections during past low sea levels (e.g., unlike Trinidad and possibly Tobago; Murphy, 1997) implies efficient marine dispersal (Hedges et al., 1992) and rafting (Boos, 1984a,b; Censky et al., 1998; Heinicke et al., 2007). In addition, the presence of $E$. juliae in different islands (although a taxonomical assessment is lacking), Guadaloupe, Dominica, and Marie-Galante, further supports the ability of these species to disperse over sea and colonize new habitats (Fig. 1).

Applying mitochondrial genetic divergence for gene fragments in Squamata (16S: $0.45 \%$ and 12 S: $0.5 \%$, Carranza et al., 2004; Poulakakis et al., 2005, respectively) to our uncorrected distances (Table 3) suggests an E. juliae-E. cursor genetic split at around 2 million yr. Nevertheless, caution is needed in interpreting such estimation as it is out of the scope of our main study and can only be considered as a rough divergence estimate.

The two most recent E. cursor specimens were collected from Diamond Rock in 1964 
Table 3.-Extended.

\begin{tabular}{|c|c|c|c|c|c|c|c|c|c|c|c|c|c|c|c|}
\hline E.alm & E.atr & E.cei & E.poe & L.fla & L.mer & L.ano & L.ele & L.pau & X.sev & X.wer & X.neu & X.mer & X.dor & X.his & P.job \\
\hline 44 & 45 & 39 & 38 & 75 & 76 & 80 & 77 & 41 & 78 & 79 & 64 & 36 & 6 & 64 & 99 \\
\hline 43 & 32 & 3 & 34 & 7 & 7 & 8 & 8 & 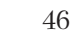 & & & & 37 & & 75 & 99 \\
\hline 38 & 29 & 28 & 27 & 74 & 74 & 76 & 74 & 37 & 71 & 3 & 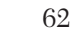 & 31 & 59 & 67 & 98 \\
\hline 23 & 19 & 35 & 34 & 76 & 80 & 80 & 78 & 41 & 75 & 8 & 66 & 32 & 58 & 67 & 102 \\
\hline 33 & 24 & 23 & 22 & 6 & 68 & 70 & 67 & 43 & 66 & 66 & 6 & 32 & 55 & 61 & 90 \\
\hline 38 & 28 & 30 & 30 & 69 & 72 & 71 & 69 & 45 & 6 & 70 & 6 & 33 & 52 & 64 & 95 \\
\hline 45 & 31 & 30 & 29 & 70 & 71 & 72 & 69 & 43 & 75 & 71 & 61 & 34 & 57 & 62 & 94 \\
\hline 39 & 29 & 23 & 22 & 72 & 73 & 77 & 75 & 40 & 66 & 69 & 64 & 39 & 51 & 60 & 96 \\
\hline 34 & 29 & 24 & 23 & 70 & 72 & 75 & 72 & 42 & & & & & 47 & 56 & 95 \\
\hline 35 & 2 & 1 & 1 & 6 & 60 & 6 & 6 & 3 & & & & & & 7 & 90 \\
\hline 36 & 2 & 2 & 2 & 7 & 7 & 8 & 78 & 4 & & & 5 & 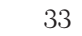 & & 1 & 106 \\
\hline 35 & 2 & 2 & 2 & 7 & 7 & 74 & 79 & & & & & & & 9 & 102 \\
\hline 3 & 2 & 2 & 1 & 6 & 69 & 7 & 68 & & & & & 2 & & 5 & 97 \\
\hline 37 & 2 & 2 & 2 & 77 & 77 & 8 & 78 & 4 & & & 6 & 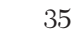 & & 64 & 108 \\
\hline 37 & 30 & 26 & 2 & 74 & 73 & 75 & 75 & 3 & 6 & 7 & 5 & 32 & 5 & 61 & 104 \\
\hline - & 29 & 36 & 3 & 71 & 78 & 77 & 75 & 41 & 6 & & 6 & 7 & 61 & 66 & 101 \\
\hline 0,04 & - & 27 & 26 & 72 & 75 & 74 & 72 & 39 & 6 & & 5 & 31 & 5 & 61 & 99 \\
\hline 0,05 & 038 & - & 1 & 75 & 76 & 78 & 77 & & & & 6 & 33 & & 61 & 101 \\
\hline 0,049 & 036 & 001 & - & 74 & 75 & 77 & 76 & 4 & & & & 34 & & 62 & 102 \\
\hline 0,1 & 102 & 106 & 10 & - & 30 & 48 & 46 & 20 & & & $7 i$ & 41 & & 63 & 98 \\
\hline 0,11 & 105 & & & 042 & - & 56 & 55 & 3 & 7 & & 7 & 45 & & 71 & 100 \\
\hline 108 & $10 \mathrm{~s}$ & & & 067 & 078 & - & 5 & 31 & & & 7 & 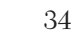 & 0 & 72 & 101 \\
\hline 105 & 101 & & & & & م07 & - & 3 & & 7 & 7. & 2 & 0 & 72 & 99 \\
\hline 125 & 119 & & 132 & 061 & 95 & 095 & 095 & - & 42 & 40 & 44 & 46 & 4 & 42 & 52 \\
\hline 098 & 101 & 098 & & 099 & 0107 & 113 & 111 & 134 & - & 61 & 6 & 26 & & 56 & 98 \\
\hline 106 &, 096 & 0,092 & 093 & 105 & 0,122 & 0,113 & 0,111 & 0,14 & 093 & - & 59 & 20 & & 52 & 105 \\
\hline 0,094 & 0,081 & 085 & 0087 & 0,103 & 0,101 & 0,098 & 0,101 & 0,135 & 0,098 & 0,092 & - & 26 & 37 & 49 & 111 \\
\hline 0,113 & 0,092 & 101 & 0,104 & 125 & 0,138 & 0,104 & 0,098 & 141 & 0,083 & 0,07 & 0,08 & - & 28 & 28 & 43 \\
\hline 0,094 & 0,079 & 083 & 0,085 & 098 & 0,105 & 0,1 & 0,1 & 126 & 0,091 & 0,084 & 0,057 & 0,086 & - & 13 & 91 \\
\hline 0,092 & 0,085 & 085 & 0,087 & 089 & 0,1 & 0,1 & 0,1 & 0,129 & 0,083 & 0,081 & 0,068 & 0,086 & 0,02 & - & 95 \\
\hline 0,141 & 0,138 & 0,141 & 0,142 & 0,137 & 0,14 & 0,14 & 0,138 & 0,159 & 0,145 & 0,162 & 0,154 & 0,131 & 0,14 & 0,132 & - \\
\hline
\end{tabular}

and 1968 (Breuil, 2009). Genetic and morphological analyses of such snakes may prove important to assess if they share in fact the same E. cursor haplotype as Martinique main island populations. Thus, they could belong to a different evolutionary lineage or even a new subspecies. Furthermore, genetic divergence between the suspected extinct Martinique $E$. cursor and those in Diamond Rock may give an insight to the date at which the islet was colonized, and the level of genetic isolation at such.

\section{Suspected Ecology of E. cursor on Diamond Rock}

Although the family Xedontini includes around 40 species, occurring from the Antilles and continental Central America to southern South America (Dixon, 1989), very little is known about their ecology and diet. The few studies on their trophic ecology, mostly obtained from preserved specimens, revealed that their diet consists primarily of anurans (including tadpoles). For example, Albarelli and Santos-Costa (2010) studied the diet of $E$. reginae semilineatus from Brazil on the basis of the analysis of 182 preserved specimens, among which $95 \%$ contained exclusively anurans (e.g., Leptodactylus sp. and Physalaemus ephippifer) and 5\% contained both anurans and lizards. Similarly, Pinto and Fernandes (2004) only found Leptodactylidae, Bufonidae, and Hylidae in the diet of $E$. poecilogyrus from Brazil. Thus, little ecological information is available on E. cursor and the close phylogenetic relationship between $E$. cursor and E. juliae may help us to give some light to the former's ecology. For example, E. juliae preys mostly on frogs (Eleutherodactylus spp.) and lizards (Anolis 
spp.) throughout different habitats (Schwartz and Henderson, 1991; Breuil, 2002). This trend was also confirmed by two studies on Erythrolamprus cursors' diet (Henderson 2004), finding both prey types and a small percentage of insects in their stomachs (Henderson and Bourgeois, 1993) in both $E$. cursor and E. juliae, which is not surprising considering local abundance of frogs and lizards (Ovaska, 1991; Roughgarden, 1995). However, extirpation of E. cursor in Martinique after the introduction of mongooses and their probable last refuge in Diamond Rock is likely to have modified its ecology, consequently requiring a specific adaptation to this ecosystem. Diamond Rock is $175 \mathrm{~m}$ high and formed of dacite lava with specific vegetation, (e.g., Cereus sp., Tabebula heterophylla, Capparis flexuosa, Ficus citrifolia, and Plumeria alba) and a surface area not exceeding 5.8 ha. The completely different biotope of Diamond Rock compared with the Martinique mainland is likely associated with a distinct animal community in the islet. Moreover, the absence of their most important prey, anurans, further differentiates both ecosystems. Four are E. cursors' potential prey in Diamond Rock, Martinique's Anole (Anolis roquet ssp.), the Rough-Scaled Worm Lizard (Gymnophthalmus pleii), Vincent's Least Gecko (Sphaerodactylus vincenti adamas), and the Turnip-Tailed Gecko (Thecadactylus rapicauda). Moreover, the Black Rat (R. rattus) and the House Mouse (Mus musculus domesticus) were probably introduced during the Napoleonic Wars (Breuil, 2009). Thus, E. cursor is likely to have undergone a dietary shift, predating other prey items (e.g., small rodents, seabird eggs) or lizards.

Besides changing the trophic ecology, this new ecosystem has probably long-term consequences to fitness and reproductive success. Information on E. juliae clutch size suggests not more than four eggs (Schwartz and Henderson, 1991), a number similar to that of E. cursor, five eggs (Arlington and Henderson, 2004). Thus, because of the islet limited geographical scale, and lack of $E$. cursor recent sightings in Diamond Rock, we assume that an active breeding female population, if any, must be quite low.

\section{Conservation Implications}

An extensive survey at Diamond Rock is pivotal to establish the survival of E. cursor. If confirmed, a thorough population sampling is needed to establish the likely presence of a genetic bottleneck, thus reduced genetic richness, ultimately leading to fitness decline and possible population declines and even extinction. If sighted, an urgent conservation program will be required, and a captive breeding program has to be organized to guarantee the survival of $E$. cursor in the wild. In addition, a reintroduction program of the snake in mongoose-free areas on the Martinique main island could be expected. Diamond Rock has full protection status (Arrêté de Protection de Biotope [Habitat Protection Order]) and has been fitted with video cameras to study bird populations. Yet, the elusive racer remains unseen. Furthermore, genetic analyses from the Diamond Rock population should verify if it is a subspecies of $E$. cursor, a distinct species, or a subspecies of another species.

Control programs of invading alien species, including the eradication of rodents from islands, have been increasing in numbers in the last few decades (Myers et al., 2000; Nogales et al., 2004; Campbell and Donlan, 2005; Martins et al., 2006; Howald et al., 2007). Predator eradication programs in the West Indies have shown to have positive effects on native species. For example, on Great Bird Island off Antigua, eradication of $R$. rattus led to a $100 \%$ recovery of the snake Alsophis antiguae only in $3 \mathrm{yr}$ (Varnham et al., 1998), a snake species that had disappeared from the Antigua main island. Similarly, eradication of $H$. auropunctatus on the islet of Fajou off Guadeloupe (Lorvelec et al., 2004) and R. rattus on the islet of Sainte-Anne off Martinique showed a positive effect on native species (Pascal et al., 2004). Similarly $S$. micropithecus, an endemic gecko from Puerto Rico, recovered after the eradication of $R$. rattus from the satellite island of Monito (Schwartz and Henderson, 1991). Although there is a clear need to formally define the impact of alien species on invaded communities (Parker et al., 1999), this is balanced by a delicate trade-off between the necessity to better understand the focal ecosystem and an 
obligation to act fast (Simberloff, 2003). Thus, the eradication of rodents ( $R$. rattus and $M$. musculus) from Diamond Rock deserves consideration to preserve the last known population of E. cursor (and possibly seabirds too), but a minimal study of the trophic relationship of the focal invasive rodent species within the invaded ecosystem is crucial to design the most suitable control strategy, avoid possible trophic chain reaction, and ensure conservation success on all fronts (Caut et al., 2009).

Acknowledgment.-This work was funded by the Consejo Superior de Investigaciones Cientıficas (JAE postdoctoral contract to SC).

\section{Literature Cited}

Albarelli, L.P., and M.C. Santos-Costa 2010. Feeding ecology of Liophis reginae semilineatus (Serpentes: Colubridae: Xenodontinae) in Eastern Amazon, Brazil. Zoologia 27:87-91.

Arlington, J., and R.W. Henderson. 2004. Communal nesting site in the snake Liophis juliae in Dominica, West Indies. Caribbean Journal of Science 40:263-265.

Boos, H.E.A. 1984a. A consideration of the terrestrial reptile fauna on some offshore islands north west of Trinidad. Living World, Journal of Trinidad and Tobago Field Naturalist Club 1984:19-26.

Boos, H.E.A. 1984b. Reptiles of Soldado Rock, Living World, Journal of Trinidad and Tobago Field Naturalist Club 1984:12.

Breuil, M. 2002. Histoire naturelle des amphibiens et reptiles terrestres de l'Archipel Guadeloupéen. Guadeloupe. Saint-Martin, Saint-Barthélemy. Service du Patrimoine Naturel, Patrimoines naturels No. 54. Paris, MNHN, Institut d'Écologie et de Gestion de la Biodiversité, France.

Breuil, M. 2009. The terrestrial herpetofauna of Martinique: Past, present, future. Applied Herpetology 6:123149.

Campbell, K., and C.J. Donlan. 2005. Feral goat eradications on islands. Conservation Biology 19:1362-1374.

Carranza, S., E.N. Arnold, and F. Amat. 2004. DNA phylogeny of Lacerta (Iberolacerta) and other lacertine lizards (Reptilia: Lacertidae): did competition cause long-term mountain restriction? Systematic Biology 2:57-77.

Caut, S., E. Angulo, and F. Courchamp. 2009. Avoiding surprise effects on Surprise Island: alien species control in a multi-trophic level perspective. Biological Invasions 11:1689-1703.

Censky, J., K. Hodge, and J. Dulhey. 1998. Over-water dispersal of lizards due to hurricanes. Nature 395:556.

Crowley, B. 2011. Extinction and rediscovery: where the wild things are. Journal of Biogeography 38:1633-1634.

Dixon, J.R. 1980. The Neotropical colubrid snake genus Liophis: the generic concept. Milwakee Public Museum. Contributions in Biology and Geology 31:1-40.
Dixon, J.R. 1989. A key and checklist of the Neotropical snake genus Liophis with country list and maps. Smithsonian Herpetological Information Service 79:128.

Fisher, D.O. 2011. Cost, effort and outcome of mammal rediscovery: neglect of small species. Biological Conservation 144:1712-1718.

Fisher, D.O., and S.P. Blomberg. 2011. Correlates of rediscovery and the detectability of extinction in mammals. Proceeding of the Royal Society of London Series B Biological Sciences 278:1090-1097.

Gouy, M., S, Guindon, and O. Gascuel. 2010. SeaView version 4: a multiplatform graphical user interface for sequence alignment and phylogenetic tree building. Molecular Biology and Evolution 27:221-224.

Grazziotin, F.G., H. Zaher, R.W. Murphy, G. Scrocchi, M.A. Benavides, Y.-P. Zhang, and S.L. Bonatto. 2012. Molecular phylogeny of the New World Dipsadidae (Serpentes: Colubroidea): a reappraisal. Cladistics 1:123.

Hedges, S.B., C.A. Hass, and L.R. Maxzon. 1992. Caribbean biogeography: molecular evidence for dispersal in West Indian terrestrial vertebrates. Proceedings of the National Academy of Sciences USA 89:1909-1913.

Heinicke, M.P., W.E. Duellman, and S.B. Hedges. 2007. Major Caribbean and Central American frog faunas originated by ancient oceanic dispersal. Proceedings of the National Academy of Sciences USA 104:887-892.

Henderson, R.W. 1992. Consequences of predator introduction and habitat destruction on amphibians and reptiles in the post-Columbus West Indies. Caribbean Journal of Science 28:1-10.

Henderson, R.W. 2004. Lesser Antillean snake faunas: distribution, ecology, and conservation. Oryx 38:311320.

Henderson, R.W., and R.W. Bourgeois. 1993. Notes on the diets of West Indian Liophis (Serpentes: Colubridae). Caribbean Journal of Science 29:253-254.

Honegger, R.E. 1981. List of amphibians and reptiles either known or thought to have become extinct since 1600. Biological Conservation 19:141-158.

Howald, G., C.J., Donlan, J.P. Galvan, J.C. Russell, J. Parkes, A. Samaniego, Y.W. Wang, D. Veitch, P. Genovesi, M. Pascal, A. Saunders, and B. Tershy. 2007. Invasive rodent eradication on islands. Conservation Biology 21:1258-1268.

Huelsenbeck, J.P., and F. Ronquist. 2001. MrBayes: Bayesian inference of phylogeny. Bioinformatics 17:754-755.

Kocher, T.D., W.K. Thomas, A. Meyer, S.V. Edwards, S. Paabo, F. Villablanca, and A.C. Wilson. 1989. Dynamics of mitochondrial DNA evolution in animals: amplification and sequencing with conserved primers. Proceedings of the National Academy of Sciences USA 86:6196-6200.

Ladle, R.J., P. Jepson, A.C.M. Malhado, S. Jennings, and M. Barua. 2011. The causes and biogeographical significance of species rediscovery. Frontiers of Biogeography 3:111-117.

Larkin, M.A., G. Blackshields, N.P. Brown, R. Chenna, P.A. Mcgettigan, H. Mcwilliam, F. Valentin, I.M. Wallace, A. Wilm, R. Lopez, J.D. Thompson, T.J. 
Gibson, and D.G. Higgins. 2007. Clustal W and clustal $\mathrm{X}$ version 2.0. Bioinformatics 23:2947-2948.

Lazell, J.D. 1967. Wiederentdeckung von zwei angeblich ausgestorbenen Schlangenarten der westindischen Inseln. Salamandra 3:91-97.

Lorvelec, O., X. Delloue, M. Pascal, and S. Mege. 2004. Impacts des mammifères allochtones sur quelques espèces autochtones de l'Îlet Fajou (Réserve Naturelle du Grand Cul-de-Sac Marin, Guadeloupe), établis à l'issue d'une tentative d'éradication. Revue d'Écologie (Terre and Vie) 59:293-307.

Lorvelec, O., M. Pascal, C. Pavis, and P. Feldmann. 2007. Amphibians and reptiles of the French West Indies: inventory, threats and conservation. Applied Herpetology 4:131-161.

Martins, T.L.F., M.D. Brooke, G.M. Hilton, S. Farnsworts, J. Gould, and D.J. Pain. 2006. Costing eradications of alien mammals from islands. Animal Conservation 9:439-444.

Meusnier, I., G.A.C. Singer, J.F. Landry, D.A. Hickey, P.D.N. Hebert, and M. Hajibabaei. 2008. A universal DNA mini-bar code for biodiversity analysis. BMC Genomics 9:214.

Moreau de Jonnes, A. 1818. Monographie de la Couleuvre couresse des Antilles Coluber cursor de Lacépède. Journal de Physique 87:193-200.

Murphy, J. 1997. Reptiles and Amphibians of Trinidad and Tobago. Krieger Publication Company, USA.

Myers, N., R.A. Mittermeier, C.G. Mittermeier, G.A.B. Da Fonseca, and J. Kent. 2000. Biodiversity hot spots for conservation priorities. Nature 403:853-858

Nogales, M., A. Martín, B.R. Tershie, C.J. Donlan, D. Veitch, N. Puerta, N. Wood, and J. Alonso. 2004. A review of feral cat eradication on islands. Conservation Biology 18:310-319.

Ovaska, K. 1991. Reproductive phenology, population structure, and habitat use of the frog Eleutherodactylus johnstonei in Barbados, West Indies. Journal of Herpetology 25:424-430.

Palumbi, S.R., A.P. Martin, S. Romano, W.O. Mcmillan, L. Stice, and G. Grabowski. 1991. The Simple Fool's Guide to PCR, Version 2.0. Department of Zoology and KEwalo Marine Laboratory, USA. (Published and distributed by the authors.)

Parker, M., D. Simberloff, W.M. Lonsdale, K. Goodell, M. Wonham, P.M. Kareiva, M.H. Williamson, B. Von Holle, P.B. Moyle, J.E.L.G. Byers, and L. Goldwasser. 1999. Impact: toward a framework for understanding the ecological effects of invaders. Biological Invasions 1:3-19.

Pascal, M., R. Brithmer, O. Lorvelec, and N. Venumiere. 2004. Conséquences sur l'avifaune nicheuse de la réserve naturelle des îlets de Sainte-Anne (Martinique) de la récente invasion du rat noir (Rattus rattus), établies à l'issue d'une tentative d'éradication. Revue d'Ecologie (Terre Vie) 59:309-318.

Pinto, R.R., and R. Fernandes. 2004. Reproductive biology and diet of Liophis poecylogirus poecylogirus
(Serpentes, Colubridae) from southeastern Brazil Phyllomedusa 3:9-14.

Posada, D. 2008. jModelTest: Phylogenetic model averaging: Molecular Biology and Evolution 25:1253-1256.

Poulakakis, N., P.T. Lymberakis, C.S. Sigenopoulos, A. Magoulas, and M. Mylonas. 2005. Phylogenetic relationships and evolutionary history of snake-eyed skink Ablepharus kitaibelii (Sauria: Scincidae). Molecular Phylogenetics and Evolution 34:245-256.

Powell, R., and R.W. Henderson. 2005. Conservation status of Lesser Antillean reptiles. Iguana 12:63-77.

Powell, R., and R.W. Henderson. 2012. Island lists of West Indian amphibians and reptiles. Bulletin of the Florida Museum of Natural History 51:85-166.

Roughgarden, J. 1995. Anolis Lizards of the Caribbean: Ecology, Evolution, and Plate Tectonics. Oxford University Press, USA.

Sambrook, J., E.F. Fritsch, and T. Maniatis. 1989. Molecular Cloning: A Laboratory Manual. Cold Spring Harbor Laboratory Press, USA.

Scheffers, B.R., D.L. Yong, J.B.C. Harris, X. Giam, and N.S. Sodhi. 2011. The world's rediscovered species: back from the brink? PLoS ONE 6 e22531.

Simberloff, D. 2000. Extinction-process of island species: causes and management implications. Raffles Bulletin of Zoology 48:1-9.

Simberloff, D. 2003. How much information on population biology is needed to manage introduced species? Conservation Biology 17:83-92.

Schwartz, A., and R.W. Henderson, 1991. Amphibians and Reptiles of the West Indies. Descriptions, Distributions and Natural History. University of Florida Press, USA.

Swofford, D. 2002. PAUP* Phylogenetic Analysis Using Parsimony ("and other methods), Version 4. Sinauer Associates, USA.

Varnham, K., T. Ross, J. Daltry, M. Day, G. Cooper, and K. Lindsay. 1998. Recovery of the Antiguan racer. Aliens 8:21.

Vidal, N., M. Dewynter, and D.J. Gower. 2010. Dissecting the major American snake radiation: a molecular phylogeny of the Dipsadidae Bonaparte (Serpentes, Caenophidia). Comptes Rendus Biologies 333:48-55.

Wandeler, P., P.E. Hoeck, and L.F. Keller. 2007. Back to the future: museum specimens in population genetics. Trends in Ecology and Evolution 22:634-642.

Zaher, H., F.G. Grazziotin, J.E. Cadle, R.W. Murphy, J.C. De Moura-Leite, and S.L. Bonatto. 2009. Molecular phylogeny of advanced snakes (Serpentes, Caenophidia) with an emphasis on South American Xenodontines: a revised classification and descriptions of new taxa. Papéis Avulsos de Zoologia 49:115-153. 